\title{
Global Research Output on Sleep Research in Athletes from 1966 to 2019: A Bibliometric Analysis
}

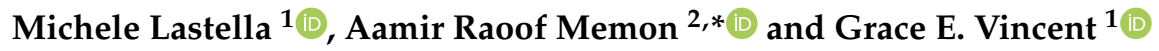 \\ 1 Appleton Institute of Behavioural Science, Central Queensland University, Adelaide 5034, \\ South Australia, Australia; m.lastella@cqu.edu.au (M.L.); g.vincent@cqu.edu.au (G.E.V.) \\ 2 Institute of Physiotherapy and Rehabilitation Sciences, Peoples University of Medical and Health Sciences \\ for Women, Nawabshah (SBA), Sindh, Pakistan \\ * Correspondence: dpt.aamir@gmail.com; Tel.: +92-3337050540
}

Received: 23 February 2020; Accepted: 25 March 2020; Published: 30 March 2020

\begin{abstract}
This study examined sleep research in athletes published between 1966 and 2019, through a bibliometric analysis of research output in the Scopus database. Following a robust assessment of titles, the bibliometric indicators of productivity for studies included in the final analysis were: Distribution of publications and citations (excluding self-citations), top ten active journals, countries, institutions and authors, single- and multi-country collaboration, and 25 top-cited papers. Out of the 1015 papers, 313 were included in the final analysis. The majority of the papers were research articles $(n=259$; $82.8 \%)$ and published in English $(n=295 ; 94.3 \%)$. From 2011, there was a dramatic increase in papers published $(n=257 ; 82.1 \%)$ and citations $(n=3538 ; 91.0 \%)$. The number of collaborations increased after 2001, with papers published through international $(n=81 ; 25.9 \%)$ and national $(n=192 ; 61.3 \%)$ collaboration. Australia was the most prolific country in terms of number of publications $(n=97$; $31.0 \%)$, and citations ( $n=1529 ; 15.8 \%)$. In conclusion, after the beginning of the twenty-first century, the scientific production on sleep research in athletes has seen significant growth in publication and citation output. Future research should focus on interventions to improve sleep in athletes.
\end{abstract}

Keywords: athletic; bibliometrics; research output; scientific production; sports; sleep

\section{Introduction}

Sleep is a basic requirement for human health and serves critical psychological and physiological functions [1,2]. To maintain optimal health and functioning, adults should obtain at least $7 \mathrm{~h}$ of sleep per night [3]. Epidemiological and experimental studies have shown that not obtaining adequate sleep is linked to a number of adverse psychological and physiological outcomes, including impairments to cognitive performance [4,5], mood [6], appetite regulation [7], as well as critical metabolic [8], and immunologic processes [9]. Sleep has long been identified by athletes and coaches as a critical component for training and competition. In recent years, there has been a dramatic increase in studies investigating the relationship between sleep, recovery, and athletic performance $[10,11]$. For athletes, frequent exposure to high training loads and competition demands increases recovery needs, and therefore, may increase their overall sleep requirement [10]. The first study to investigate relationships between sleep, recovery and performance in athletes was conducted by Baekeland et al. [12]. The authors noted increases in Slow Wave Sleep (SWS) following strenuous afternoon exercise. However, the next seminal investigation was not until 30 years later where Taylor et al. [13], noted increases in SWS during an athletic peak competitive phase. This study initiated a substantial increase in studies examining the impact of sleep in athletes, including relationships with training [14], competition [15,16], injury [17], psychological well-being [18], and performance [19]. However, to date, this growth in research has not been captured empirically. 
Bibliometric techniques aim to understand the research trends and focus, and contributions to scholarship by any field, country, institution, author or a journal $[20,21]$. The outcomes of these techniques are important for funding agencies, as they provide objective information about the quantity and quality of the research activity [22-25]. Further, examining author keywords and/or content analysis reveals current and future trends within a specific field $[22,23,26,27]$. The utilisation of bibliometric analyses are becoming increasingly common across a number of fields, including physiotherapy, human trafficking, road traffic injuries, m-health, nursing and midwifery and physical activity and sleep [27-34]. Previous studies have attempted to catalogue the evolution of sleep research, sleep research in medicine and biology, and trends in sleep research through bibliometric techniques, but the existing evidence is more than a decade old [35-37]. In addition, a bibliometric analysis of sleep research in athletes has not been conducted to date. Therefore, the aim of this study was to conduct a bibliometric analysis of sleep research in athletes. Although different databases, such as Web of Science, PubMed/Medline and SPORTDiscus may be used to achieve this, Scopus was used in the current study because of its advantages over other bibliographic databases [38-40]. The findings of this study will provide an in-depth insight into the current state of the literature and trends in the area of sleep in athletes and provide directions for future research.

\section{Materials and Methods}

\subsection{Database and Search Strategy}

This study does not involve human subjects, and therefore, did not require ethics approval. Scopus (https://www.scopus.com/) was used because it is a multidisciplinary bibliographic database, covering over 23000 peer-reviewed journals, and is one of the largest research databases [40]. Scopus is also commonly used in bibliometric studies [27,31-34,41]. Bibliometric analyses differ from the methodology employed in systematic reviews; the discussion about the typology of reviews could be found elsewhere [20,41-43]. The use of title search is common in bibliometric studies in contrast to the title-abstract-keywords search query [32-34,41]. The search strategy for the current study was informed by the methodology used in previous bibliometric analyses [28,31,34,41].

Use of appropriate and relevant keywords is essential for improving the accuracy of the findings, and it directly affects the findings of a bibliometric study [33]. In order to determine relevant keywords, several recent systematic reviews on sleep in athletes were examined [10,44-46]. The literature search was performed following several steps to ensure that the retrieved results were obtained with maximum accuracy, limiting the likelihood of false positive results. First, an online search of the literature on sleep in athletes was conducted via the Scopus database on August 14, 2019. The results of the initial search strategy were assessed by all the authors to ensure that all relevant keywords were included and the first paper on sleep in athletes was identified; it was decided that the retrieved literature will cover the period from 1965 to 2019 because the first paper about sleep in athletes was published in 1966 [12]. Second, the inclusion and exclusion criteria were then refined to reduce the likelihood of false positive results. Finally, a randomly selected list of titles was assessed twice, and after an extensive discussion, a final search query was run on August 21, 2019. Eighty general and specific keywords for searching the literature on sleep in athletes were used, which included "sleep*", "sleep quantity", "sleep quality", "sleep-hygiene", "sleep disturbance", "nap*", "wak", "wake", "athlet", "player*", "sport", , competit", "team sport",

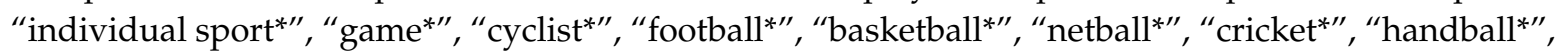

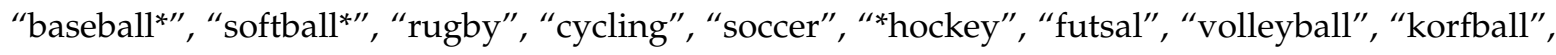
"lacrosse", "curling", "polo", "*swimming", "rowing", "mountain biking", "triathlon", "race walking", "canoeing", "diving", "running", "judo", "*skating", "ballet", "skiing", "snowboarding", "taekwondo", "archery", "badminton", “bmx", "bocce", "bowling", "boxing", "cheerleading", "croquet", "dance", "fencing", "golf", "gymnastics", "martial arts", "squash", "throw", "*tennis", "karate", "touch football*", "ice-hockey", "synchronised swimming", "swimming", "speed skating", "figure skating", "table tennis", "weight lift", , "roller skating", "motor sport", "orienteering", "equestrian", "wheelchair 
prop", "water polo", "abseiling", and "surfing". The keywords were combined using Boolean operators (AND and OR), and wild cards/truncations were used with some keywords to look for their word variants (Appendix A).

\subsection{Inclusion and Exclusion Criteria}

Studies exploring sleep in athletes were included. An athlete was defined as someone who "engages in physical activity or sports with the primary goal of improving performance to bolster athletic excellence and/or achievement" [47-49]. This included 'recreational', 'retired', 'semi-elite', 'competitive elite', 'successful elite' and 'world-class elite' athletes [47-49]. Recreational athletes were defined as "recreational participants who are adequately trained and adequately skilled to be categorised as athletes" [47]. Retired athletes referred to the athletes who took retirement from their sport career. Swann et al. provide the definition of semi-elite, competitive elite, successful elite and world-class elite athletes [49]. Studies that investigated clinical sleep disorders in athletes (such as insomnia, rapid eye movement (REM) sleep behaviour disorder, parasomnias, circadian rhythm disorders, sleep-related movement disorders, etc.) were included. Furthermore, studies investigating the relationship between sleep and health outcomes (e.g., depression, body temperature, etc.) in athletes were included.

The exclusion criteria were: (1) Studies on non-athletic populations (e.g., healthy sedentary or physically active participants), industrial or occupational athletes (e.g., military personnel, firefighters) were excluded; (2) studies validating a tool/device or methodological studies (i.e., accelerometer algorithms for sleep, psychometric properties of questionnaires, etc.) in athletes; (3) studies conducted on animals; and (4) studies published in languages other than English lacking an English abstract. In the case of papers published in English but without an abstract, abstracts were manually searched to determine the inclusion of the paper.

Only papers published in journals were included, whereas, books, book chapters, and conference proceedings were excluded from analyses. Errata papers were also excluded from the analyses, but conference papers were included (as they cannot be published twice). To encompass all the relevant literature, irrespective of the language of publication, in this bibliometric analysis, no restrictions were made for the language of the published papers.

\subsection{Data extraction, Validation and Analysis (Bibliometric Indicators and Mapping)}

Two authors (ML and GV) independently scored 25 randomly selected titles and abstracts for inclusion or exclusion. This was done three times to validate the search strategy and ensure the appropriateness of the inclusion and exclusion criteria. Following this, two authors (ML and GV) independently reviewed the titles and abstracts of all the papers $(n=884)$ and irrelevant papers (i.e., not meeting the inclusion/exclusion criteria) $(n=507)$, papers not published in English that are without abstract $(n=35)$ and duplicate papers $(n=3)$ were excluded. Fifty-five papers, where the two authors (ML and GV) were unsure, were discussed among all authors (ML, GV, and ARM) and irrelevant papers (26 out of 55) were excluded. Finally, 313 (35.4\%) papers were deemed eligible for inclusion in the final analysis (Figure 1; supplementary file). 


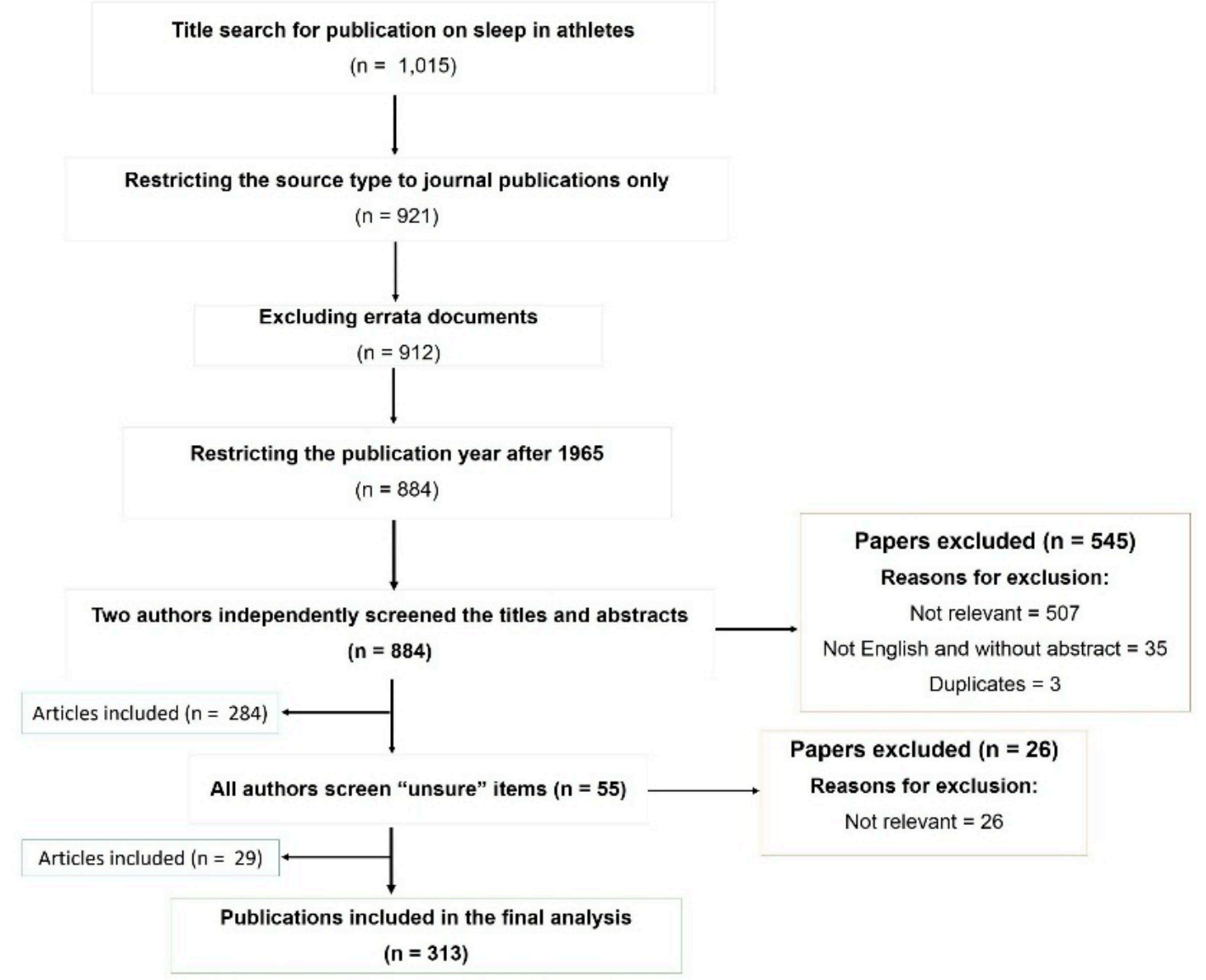

Figure 1. Flow diagram for title selection for bibliometric analysis.

The data for retrieved papers were imported directly from the Scopus database as a CSV (comma-separated values) file and analysed using Microsoft Excel 2013 (Microsoft Corporation, Santa Rosa, California, USA), SPSS v20, and VOSViewer program. The study findings were presented through graphs, tables and network visualisation maps. The following information for the papers was included in the final analysis: The type of the papers, the total number of papers, total number of citations to the retrieved papers (excluding self-citations), 10 most active journals, countries, institutions and authors, and 25 top-cited papers. Growth in the number of publications was reported through stratified growth rate (SGR) across six strata of nine years period, including period-1 (1966-1974), period-2 (1975-1983), period-3 (1984-1992), period-4 (1993-2001), period-5 (2002-2010) and period-6 (2011-2019). The SGR was a modification of the annual growth rate (AGR), and was based on the equation: (Ending Value - Beginning Value)/Beginning Value] $\times 100$ [34]. After excluding the self-citations, the number of citations and citations per paper were calculated and reported across these six time periods. Authorship pattern was determined by calculating number of single- and multi-authored papers, the total number of authors and number of authors in multi-authored papers, the average number of authors per paper. The collaboration was ascertained by calculating papers with single-country (national) and multi-country (international) collaboration. Single authored papers were also reported. In addition, author keywords were used to present the emerging trends and focus of the sleep research in athletes. The journal impacts factor (JIF), SCImago Journal Rank (SJR), and CiteScore were reported, for the leading journals publishing sleep research in athletes, as they are commonly used measures of scientific influence of scholarly journals [50,51]. The data for JIF was obtained from the Journal Citation Report (JCR) for the year 2018, SJR (https://www.scimagojr.com/) and CiteScore (https://journalmetrics.scopus.com/) from Elsevier. The Hirsch index (h-index) for the leading journals, 
authors, institutions, and countries was also reported as a proxy measure of the influence of an author, country or an institution [52,53].

For the top-cited papers, 25 papers for sleep research in athletes and their citation, the Scopus were presented. As the total number of citations has several limitations [54-56], citation density (citations per year) was used, in the current paper, as a measure to determine the impact of a research paper among the top-cited papers. Citation density (often called citation rate or citations per year) was calculated by dividing a paper's citation count (total citations) by the number of years since publication [54]. Instead of conducting a separate analysis and present it elsewhere, the cutoff of 25 papers was selected in the current study to show the most impactful papers on sleep in athletes.

The Java program VOSviewer, a freely available software by Leiden University Netherlands, was used for graphic presentation of co-authorship analysis, the co-occurrence of author keywords, and international collaboration among countries through network visualisation maps. This program is widely used to map and visualise the citation relationships $[57,58]$. The features of network visualisation maps are reflected through specific colours (clusters) representing units (i.e., keywords) belonging to one group, size of the circle and font size proportional to the productivity, occurrence, number of citations, and thickness of connecting lines indicating the strength of collaboration.

\section{Results}

\subsection{Type of Documents and Growth Pattern}

In total, 313 (35.4\%) documents were included in the final analysis. The highest number of papers by type were research articles $(n=259 ; 82.8)$, reviews $(27 ; 8.6 \%)$ and letters $(13 ; 4.2 \%)$ (Table 1$)$. All the retrieved papers were published in eight languages, with English $(295 ; 94.3 \%)$ as the most common language. Although a number of publications and citations started to grow after the early 2000s, there was a sharp increase in the number of citations after 2007, but the publication output rapidly grew only after 2011 (Figure 2). A total of 1,542 authors (ranging from 1 to 18 authors per paper) participated in publishing sleep research in athletes, with an average of 4.9 authors per paper. The national collaboration was present in $203(64.9 \%)$ papers and international in $81(25.9 \%)$ papers. In addition, 25 (8\%) papers were single-authored, and 288 (92\%) were multi-authored.

Table 1. Type of papers on sleep research in athletes.

\begin{tabular}{ccc}
\hline Type of Paper & Frequency $(\boldsymbol{n = 3 1 3 )}$ & Percentage (\%) \\
\hline Article (including articles in press) & 259 & 82.8 \\
Review & 27 & 8.6 \\
Letter & 13 & 4.2 \\
Conference Paper & 5 & 1.6 \\
Note & 4 & 1.3 \\
Short Survey & 3 & 1.0 \\
Editorial & 2 & 0.6 \\
\hline
\end{tabular}




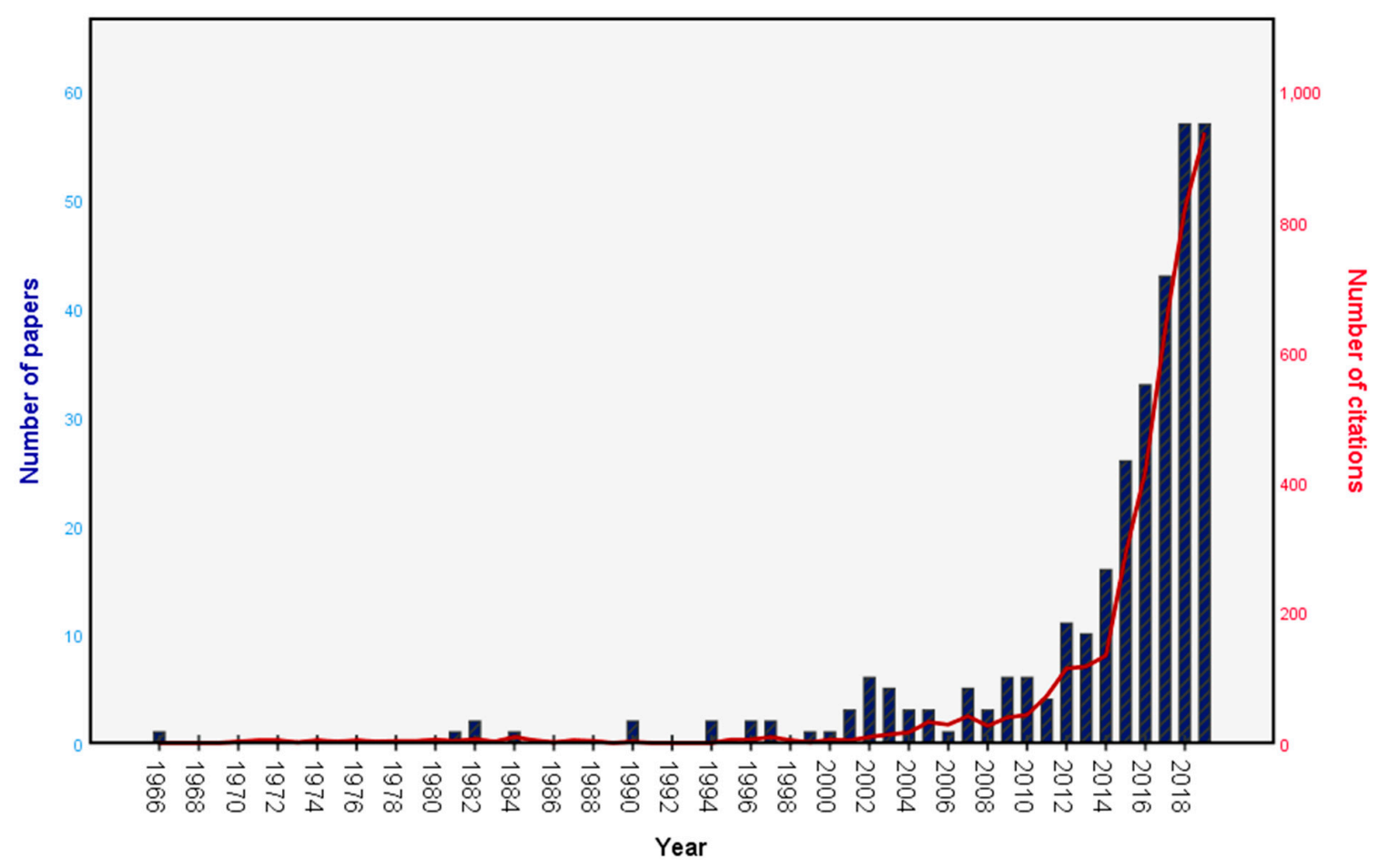

Figure 2. The growth trend for publications and citations (1966-2019).

There was only one paper published during the period from 1966 to 1974. The initial 27 years of the analysis showed output fluctuation, but after 1992, there was a continuous rise in the number of authors, average authors per paper, single-authored papers, multiple-authored papers and single country (national) collaboration (Table 2). However, multi-country (international) collaboration increased after 2001, with 81 (25.9\%) published papers published by authors through international collaboration. The period from 2011 onwards was very productive, with $257(82.1 \%)$ papers and 3538 $(91.0 \%)$ citations-a growth by $576.3 \%$. There were $57(18.2 \%)$ papers published in 2019 which, based on previous output, is predicted to rise to approximately 86 published papers by the end of the year. 
Table 2. Growth pattern for sleep research in athletes.

\begin{tabular}{|c|c|c|c|c|c|c|c|c|c|c|c|c|c|c|}
\hline $\begin{array}{l}\text { Year } \\
\text { Group }\end{array}$ & Papers & $\begin{array}{c}\text { Cumulative } \\
\text { Papers }\end{array}$ & SGR & $\begin{array}{l}\text { Citations } \\
(\text { min-max) }\end{array}$ & $\begin{array}{c}\text { Cumulative } \\
\text { Citations }\end{array}$ & CPP & Authors & AAPP & SAP & MAP & AMAP & $\begin{array}{l}\text { AAMAP } \\
\text { (min-max) }\end{array}$ & SCC & MCC * \\
\hline 1966-1974 & 1 & - & - & $15(1-4)$ & - & 15.0 & 2 & 2.0 & 0 & 1 & 2 & $2.0(2-2)$ & 0 & 0 \\
\hline 1975-1983 & 3 & 4 & 200 & $30(2-6)$ & 45 & 10.0 & 4 & 1.3 & 2 & 1 & 2 & $2.0(2-2)$ & 0 & 0 \\
\hline 1984-1992 & 3 & 7 & 0 & $23(0-9)$ & 68 & 7.7 & 13 & 4.3 & 1 & 2 & 12 & $6.0(6-6)$ & 2 & 0 \\
\hline 1993-2001 & 11 & 18 & 266.7 & $33(0-9)$ & 101 & 3.0 & 42 & 3.8 & 2 & 9 & 40 & $4.4(2-6)$ & 9 & 0 \\
\hline $2002-2010$ & 38 & 56 & 245.5 & $247(9-43)$ & 348 & 6.5 & 184 & 4.8 & 4 & 34 & 180 & $5.3(2-13)$ & 27 & 7 \\
\hline 2011-2019 & 257 & 313 & 576.3 & 3538 (72-937) & 3886 & 13.8 & 1297 & 5.1 & 16 & 241 & 1281 & $5.3(2-18)$ & 165 & 74 \\
\hline Total & 313 & 313 & - & $3886(0-937)$ & 3886 & 12.4 & 1542 & 4.9 & 25 & 288 & 1517 & $5.3(2-18)$ & 203 & 81 \\
\hline
\end{tabular}

SGR = stratified growth rate; $\mathrm{CPP}=$ citation per paper; $\mathrm{APP}=$ average authors per paper; $\mathrm{SAP}=$ single authored paper; $\mathrm{MAP}=$ multi authored paper; $\mathrm{AMAP}=$ authors in multi authored paper; AAMAP = average authors in multi authored paper; $\mathrm{SCC}=$ single country collaboration; MCC = multi-country collaboration. * undetermined in 4 papers. 


\subsection{Preferred Journals and Highly Cited Papers}

In total, 121 journals published the included papers, and top 10 journals published 126 (40.3\%) of the total number of papers. European Journal of Sport Science and Journal of Sports Sciences were ranked first with 17 (5.4\%) papers each, followed by International Journal of Sports Physiology and Performance $(16 ; 5.1 \%)$ and Chronobiology International $(15 ; 4.8 \%)$. In addition, h-index of the top 10 journals was in the range of 4 to 9 . Five of the top ten journals were from the UK, three from the USA, and one from the Netherlands and Italy (Table 3). There were only nine papers published in Sports Medicine, which received 355 citations (citation per paper $=39.4$ ) — the highest amongst the top 10 journals. All the journals had the journal impact factor and CiteScore above one (with Biological Rhythm Research being one exception). British Journal of Sports Medicine had the highest impact factor $(11.645 ; 5$-year IF $=9.805)$ and published $12(3.8 \%)$ papers. Seven journals belonged to Q1, two to Q2 (SJR: 0.54-0.98) and one was from Q3 $(\mathrm{SJR}=0.28)$.

From the citation analysis of 25 highly-cited papers, it was found that eighteen papers were research articles, five reviews, and two conference papers. The national collaboration was present in sixteen papers and international collaboration in six papers. Two papers were single-authored (Table 4). The highest number of citations were received by the paper titled "The effects of sleep extension on the athletic performance of collegiate basketball players" [19], which was published in Sleep in 2011, and received a total of 158 citations according to Scopus. On the other hand, the second-ranked paper was a review titled "Sleep and athletic performance: The effects of sleep loss on exercise performance, and physiological and cognitive responses to exercise" [59], with the highest citation density (29.2 citations per year since publication) and was published in 2015. The paper "Sleep in elite athletes and nutritional interventions to enhance sleep" [60] was a single-authored research article, among the top 10 highly cited papers, with 104 citations. The first paper on sleep in athletes titled "Exercise and sleep patterns in college athletes" [12], published in Perceptual and Motor Skills in 1966, was ranked 8th and had received only 103 citations (1.9 citations per year since publication). Fifteen (60\%) of the top 25 highly cited papers were published after 2010. 
Table 3. Top 10 preferred journals for sleep research in athletes $(n=313)$.

\begin{tabular}{|c|c|c|c|c|c|c|c|c|c|}
\hline Journal & Country & Papers (\%) & Citations & CPP & h-index & $\mathrm{JIF}_{2018}$ & 5-year IF & $\mathrm{SJR}_{2018}$ & CiteScore \\
\hline European Journal of Sport Science & UK & $17(5.4)$ & 239 & 14.1 & 9 & 2.376 & 2.896 & $1.17(\mathrm{Q} 1)$ & 2.75 \\
\hline Journal of Sports Sciences & UK & $17(5.4)$ & 316 & 18.6 & 8 & 2.811 & 3.264 & $1.23(\mathrm{Q} 1)$ & 2.79 \\
\hline International Journal of Sports Physiology and Performance & USA & $16(5.1)$ & 155 & 9.7 & 7 & 3.979 & 4.133 & $1.94(\mathrm{Q} 1)$ & 3.44 \\
\hline Chronobiology International & USA & $15(4.8)$ & 189 & 12.6 & 6 & 2.562 & 2.998 & $0.98(\mathrm{Q} 2)$ & 2.61 \\
\hline Biological Rhythm Research & UK & $13(4.2)$ & 85 & 6.5 & 4 & 0.773 & 0.691 & $0.28(\mathrm{Q} 3)$ & 0.85 \\
\hline Journal of Science and Medicine in Sport & Netherlands & $13(4.2)$ & 217 & 16.7 & 7 & 3.623 & 4.198 & $1.67(\mathrm{Q} 1)$ & 3.84 \\
\hline British Journal of Sports Medicine & UK & $12(3.8)$ & 132 & 11.0 & 7 & 11.645 & 9.805 & $4.14(\mathrm{Q} 1)$ & 6.02 \\
\hline Sports Medicine & UK & $9(2.9)$ & 355 & 39.4 & 6 & 7.583 & 9.257 & $3.19(\mathrm{Q} 1)$ & 7.42 \\
\hline Journal of Sports Medicine and Physical Fitness & Italy & $7(2.2)$ & 42 & 6.0 & 4 & 1.302 & 1.395 & $0.54(\mathrm{Q} 2)$ & 1.16 \\
\hline Journal of Strength and Conditioning Research & USA & $7(2.2)$ & 44 & 6.3 & 4 & 3.017 & 3.101 & $1.5(\mathrm{Q} 1)$ & 2.59 \\
\hline
\end{tabular}

CPP = citations per paper; JIF $_{2018}$ = Journal impact factor for 2018; 5-year IF = 5-year impact factor; SJR $_{2018}$ = SCImago Journal Rank for 2018.

Table 4. Top 25 highly-cited papers for sleep research in athletes.

\begin{tabular}{|c|c|c|c|c|c|}
\hline $\mathbf{R}$ & Citation of the Paper & Collaboration & Pub. Type & Citations & CD \\
\hline 1 & $\begin{array}{l}\text { Mah, C. D., Mah, K. E., Kezirian, E. J., \& Dement, W. C. (2011). The effects of sleep extension on the athletic } \\
\text { performance of collegiate basketball players. Sleep, 34(7), 943-950. }\end{array}$ & SCC & Article & 158 & 17.6 \\
\hline 2 & $\begin{array}{l}\text { Fullagar, H. H., Skorski, S., Duffield, R., Hammes, D., Coutts, A. J., \& Meyer, T. (2015). Sleep and athletic } \\
\text { performance: The effects of sleep loss on exercise performance, and physiological and cognitive responses to } \\
\text { exercise. Sports Medicine, 45(2), 161-186. }\end{array}$ & MCC & Review & 146 & 29.2 \\
\hline 3 & $\begin{array}{l}\text { Reilly, T., \& Edwards, B. (2007). Altered sleep-wake cycles and physical performance in athletes. Physiology } \mathcal{E} \\
\text { Behavior, 90(2-3), 274-284. }\end{array}$ & SCC & Article & 135 & 10.4 \\
\hline 4 & $\begin{array}{l}\text { Leeder, J., Glaister, M., Pizzoferro, K., Dawson, J., \& Pedlar, C. (2012). Sleep duration and quality in elite } \\
\text { athletes measured using wristwatch actigraphy. Journal of Sports Sciences, 30(6), 541-545. }\end{array}$ & SCC & Article & 119 & 14.9 \\
\hline
\end{tabular}


Table 4. Cont.

\begin{tabular}{|c|c|c|c|c|c|}
\hline $\mathbf{R}$ & Citation of the Paper & Collaboration & Pub. Type & Citations & CD \\
\hline 5 & $\begin{array}{l}\text { Brand, S., Gerber, M., Beck, J., Hatzinger, M., Pühse, U., \& Holsboer-Trachsler, E. (2010). High exercise levels } \\
\text { are related to favourable sleep patterns and psychological functioning in adolescents: A comparison of } \\
\text { athletes and controls. Journal of Adolescent Health, 46(2), 133-141. }\end{array}$ & SCC & Article & 118 & 11.8 \\
\hline 6 & $\begin{array}{l}\text { Ashenden, M. J., Gore, C. J., Dobson, G. P., \& Hahn, A. G. (1999). "Live high, train low" does not change the } \\
\text { total haemoglobin mass of male endurance athletes sleeping at a simulated altitude of } 3000 \mathrm{~m} \text { for } 23 \text { nights. } \\
\text { European Journal of Applied Physiology and Occupational Physiology, 80(5), 479-484. }\end{array}$ & SCC & Article & 106 & 5.1 \\
\hline 7 & $\begin{array}{l}\text { Halson, S. L. (2014). Sleep in elite athletes and nutritional interventions to enhance sleep. Sports Medicine, } \\
44(1), 13-23 .\end{array}$ & SAP & Article & 104 & 17.3 \\
\hline 8 & $\begin{array}{l}\text { Baekeland F., \& Lasky R. (1966). Exercise and sleep patterns in college athletes. Perceptual and Motor Skills, } \\
\text { 23(3), 1203-1207. }\end{array}$ & * & Article & 103 & 1.9 \\
\hline 9 & $\begin{array}{l}\text { Juliff, L. E., Halson, S. L., \& Peiffer, J. J. (2015). Understanding sleep disturbance in athletes prior to important } \\
\text { competitions. Journal of Science and Medicine in Sport, 18(1), 13-18. }\end{array}$ & SCC & Article & 86 & 17.2 \\
\hline 10 & $\begin{array}{l}\text { Gosselin, N., Lassonde, M., Petit, D., Leclerc, S., Mongrain, V., Collie, A., \& Montplaisir, J. (2009). Sleep } \\
\text { following sport-related concussions. Sleep Medicine, 10(1), 35-46. }\end{array}$ & MCC & Article & 86 & 7.8 \\
\hline 11 & $\begin{array}{l}\text { Milewski, M. D., Skaggs, D. L., Bishop, G. A., Pace, J. L., Ibrahim, D. A., Wren, T. A., \& Barzdukas, A. (2014). } \\
\text { Chronic lack of sleep is associated with increased sports injuries in adolescent athletes. Journal of Pediatric } \\
\text { Orthopaedics, 34(2), 129-133. }\end{array}$ & SCC & Article & 84 & 14 \\
\hline 12 & $\begin{array}{l}\text { Samuels C. (2008). Sleep, recovery, and performance: The new frontier in high-performance athletics. } \\
\text { Neurologic Clinics, 26(1), 169-180. }\end{array}$ & SAP & Review & 84 & 7 \\
\hline 13 & $\begin{array}{l}\text { Hynynen, E. S. A., Uusitalo, A., Konttinen, N., \& Rusko, H. (2006). Heart rate variability during night sleep } \\
\text { and after awakening in overtrained athletes. Medicine and Science in Sports and Exercise, 38(2), 313-317. }\end{array}$ & SCC & Article & 81 & 5.8 \\
\hline 14 & $\begin{array}{l}\text { Sargent, C., Lastella, M., Halson, S. L., \& Roach, G. D. (2014). The impact of training schedules on the sleep } \\
\text { and fatigue of elite athletes. Chronobiology International, 31(10), 1160-1168. }\end{array}$ & SCC & $\begin{array}{l}\text { Conference } \\
\text { Paper }\end{array}$ & 78 & 13 \\
\hline 15 & $\begin{array}{l}\text { Hausswirth, C., Louis, J., Aubry, A., Bonnet, G., Duffield, R., \& LE Meur, Y. (2014). Evidence of disturbed sleep } \\
\text { and increased illness in overreached endurance athletes. Medicine and Science in Sports and Exercise, } \\
\text { 46(5), 1036-1045. }\end{array}$ & $\mathrm{MCC}$ & Article & 75 & 12.5 \\
\hline 16 & $\begin{array}{l}\text { Lastella, M., Roach, G. D., Halson, S. L., \& Sargent, C. (2015). Sleep/wake behaviours of elite athletes from } \\
\text { individual and team sports. European Journal of Sport Science, 15(2), 94-100. }\end{array}$ & SCC & Article & 71 & 14.2 \\
\hline
\end{tabular}


Table 4. Cont.

\begin{tabular}{|c|c|c|c|c|c|}
\hline $\mathbf{R}$ & Citation of the Paper & Collaboration & Pub. Type & Citations & CD \\
\hline 17 & $\begin{array}{l}\text { Reilly, T., \& Piercy, M. (1994). The effect of partial sleep deprivation on weight-lifting performance. Ergonomics, } \\
\text { 37(1), 107-115. }\end{array}$ & SCC & Article & 68 & 2.6 \\
\hline 18 & $\begin{array}{l}\text { Erlacher, D., Ehrlenspiel, F., Adegbesan, O. A., \& Galal El-Din, H. (2011). Sleep habits in German athletes } \\
\text { before important competitions or games. Journal of Sports Sciences, 29(8), 859-866. }\end{array}$ & $\mathrm{MCC}$ & Article & 67 & 7.4 \\
\hline 19 & $\begin{array}{l}\text { Nédélec, M., Halson, S., Abaidia, A. E., Ahmaidi, S., \& Dupont, G. (2015). Stress, sleep and recovery in elite } \\
\text { soccer: A critical review of the literature. Sports Medicine, 45(10), 1387-1400. }\end{array}$ & $\mathrm{MCC}$ & Review & 62 & 12.4 \\
\hline 20 & $\begin{array}{l}\text { Thun, E., Bjorvatn, B., Flo, E., Harris, A., \& Pallesen, S. (2015). Sleep, circadian rhythms, and athletic } \\
\text { performance. Sleep Medicine Reviews, 23, 1-9. }\end{array}$ & SCC & Review & 57 & 11.4 \\
\hline 21 & $\begin{array}{l}\text { Fietze, I., Strauch, J., Holzhausen, M., Glos, M., Theobald, C., Lehnkering, H., \& Penzel, T. (2009). Sleep } \\
\text { quality in professional ballet dancers. Chronobiology International, 26(6), 1249-1262. }\end{array}$ & SCC & Article & 54 & 4.9 \\
\hline 22 & $\begin{array}{l}\text { Lastella, M., Lovell, G. P., \& Sargent, C. (2014). Athletes' precompetitive sleep behaviour and its relationship } \\
\text { with subsequent precompetitive mood and performance. European Journal of Sport Science, 14(sup1), S123-S130. }\end{array}$ & SCC & Article & 51 & 8.5 \\
\hline 23 & $\begin{array}{l}\text { McClure D.J., Zuckerman S.L., Kutscher S.J., Gregory A.J., Solomon G.S. (2014). McClure, D. J., Zuckerman, S. } \\
\text { L., Kutscher, S. J., Gregory, A. J., \& Solomon, G. S. (2014). Baseline neurocognitive testing in sports-related } \\
\text { concussions: The importance of a prior night's sleep. American Journal of Sports Medicine, 42(2), 472-478. }\end{array}$ & SCC & $\begin{array}{l}\text { Conference } \\
\text { Paper }\end{array}$ & 50 & 8.3 \\
\hline 24 & $\begin{array}{l}\text { Cardinali, D. P., Bortman, G. P., Liotta, G., Lloret, S. P., Albornoz, L. E., Cutrera, R. A., ... \& Gallo, P. O. (2002). } \\
\text { A multifactorial approach employing melatonin to accelerate resynchronisation of sleep-wake cycle after a } 12 \\
\text { time-zone westerly transmeridian flight in elite soccer athletes. Journal of Pineal Research, 32(1), 41-46. }\end{array}$ & SCC & Article & 47 & 2.6 \\
\hline 25 & $\begin{array}{l}\text { Fullagar, H. H., Duffield, R., Skorski, S., Coutts, A. J., Julian, R., \& Meyer, T. (2015). Sleep and Recovery in } \\
\text { Team Sport: Current Sleep-Related Issues Facing Professional Team-Sport Athletes. International Journal of } \\
\text { Sports Physiology and Performance, 10(8), 950-957. }\end{array}$ & MCC & Review & 42 & 8.4 \\
\hline
\end{tabular}

$\mathrm{CD}=$ citation density; $\mathrm{SAP}=$ single authored paper; $\mathrm{SCC}=$ single country collaboration; $\mathrm{MCC}=$ multi country collaboration; $\mathrm{R}=$ rank; ${ }^{*}$ did not contain data about author affiliations, thus, the type of collaboration for it could not be determined. Please note type of paper as per Scopus classification. 


\subsection{Highly Productive Countries, Institutions and Pattern of Collaboration}

Authors from 39 countries and 160 affiliations participated in publishing sleep research in athletes. The top 10 countries and institutions participated in publishing $311(99.4 \%)$ and $153(48.9 \%)$ papers, respectively. Australia was the most productive country with 97 (31.0\%) publications, 1529 (39.4\%) citations, and $49(15.7 \%)$ national and 43 (13.7\%) international collaborative papers, with an h-index of 21. A total of 520 authors from Australia contributed to publishing the papers included in this bibliometric study (Table 5). With $66(21.1 \%)$ papers, the United States was ranked second, followed by France $(25 ; 8.0 \%)$ and the United Kingdom (24;7.7\%). Four countries in the list of top 10 were from Europe, two from Asia, two from Western Pacific, one from North America, one from Latin America. Tunisia was the most productive African country with 11 (3.5\%) papers and stood at 12th in the list of highly productive countries (data not presented). Germany, with the value of 22.1, had the highest citations per paper and stood at 5th position with $20(6.4 \%)$ publications and 442 citations. The highest number of authors per paper was recorded for Brazil, with an average of 7.6 authors per paper, contributing to only $15(4.8 \%)$ publications.

Table 5. Top 10 highly productive countries for sleep research in athletes $(n=313)$.

\begin{tabular}{|c|c|c|c|c|c|c|c|c|c|}
\hline Country & $\begin{array}{c}\text { Papers } \\
(\%)\end{array}$ & Citations & CPP & h-index & SCC & MCC & SAP & $\begin{array}{l}\text { Authors } \\
\text { (min-max) }\end{array}$ & AAPP \\
\hline Australia & $97(31.0)$ & 1529 & 15.8 & 21 & 49 & 43 & 5 & $520(1-18)$ & $5.4(2.8)$ \\
\hline France & $25(8.0)$ & 297 & 11.9 & 9 & 13 & 11 & 1 & $133(1-12)$ & $5.3(2.2)$ \\
\hline United Kingdom & $24(7.7)$ & 475 & 19.8 & 10 & 12 & 12 & 0 & $111(2-8)$ & $4.6(1.7)$ \\
\hline Japan & $16(5.1)$ & 39 & 2.4 & 4 & 14 & 1 & 1 & $98(1-13)$ & $6.1(3.2)$ \\
\hline Brazil & $15(4.8)$ & 64 & 4.3 & 4 & 11 & 4 & 0 & $114(3-13)$ & $7.6(2.7)$ \\
\hline Italy & $15(4.8)$ & 46 & 3.1 & 4 & 8 & 7 & 0 & $84(3-12)$ & $5.6(2.3)$ \\
\hline New Zealand & $15(4.8)$ & 67 & 4.5 & 4 & 5 & 10 & 0 & $66(2-10)$ & $4.4(2.3)$ \\
\hline
\end{tabular}

$\mathrm{CPP}=$ citations per paper; $\mathrm{AAPP}=$ average authors per paper; $\mathrm{SAP}=$ single authored paper; $\mathrm{SCC}=$ single country collaboration; $\mathrm{MCC}=$ multi-country collaboration .

The network visualisation map for countries with minimum of five papers consisted of 15 countries in five clusters (Figure A1). The strongest collaboration was present among Australia-Germany (link strength $=13$ ), Australia-Qatar (link strength $=10$ ), and Australia-New Zealand (link strength = 7). Co-authorship network analysis for authors with at least five papers is shown in the supplementary material (Figure A2).

The top 10 most productive institutions were from Australia $(n=5)$, Brazil $(n=1)$, Germany $(n=1)$, New Zealand $(n=1)$, Qatar $(n=1)$, and the UK $(n=1)$. The Australian Institute of Sport (Australia) was ranked first and contributed to $47(15.0 \%)$ published papers, with 760 citations (h-index $=16)$. The institutions ranked at the second, third and fourth position were Central Queensland University (Australia), University of Technology Sydney (Australia) and University of Western Australia (Australia), respectively (Table 6). Universität des Saarlandes (Germany) had the highest citations per paper 30.4 and received 274 citations for $9(2.9 \%)$ published papers. 
Table 6. Top 10 highly productive institutions for sleep research in athletes $(n=313)$.

\begin{tabular}{cccccc}
\hline Affiliation & Country & Papers (\%) & Citations & CPP & h-index \\
\hline Australian Institute of Sport & Australia & $47(15.0)$ & 760 & 16.2 & 16 \\
Central Queensland University & Australia & $21(6.7)$ & 287 & 13.7 & 9 \\
University of Technology Sydney & Australia & $15(4.8)$ & 400 & 26.7 & 9 \\
University of Western Australia & Australia & $13(4.2)$ & 135 & 10.4 & 6 \\
Aspetar Orthopaedic and Sports Medicine Hospital & Qatar & $13(4.2)$ & 91 & 7.0 & 6 \\
University of Waikato & New Zealand & $10(3.2)$ & 21 & 2.1 & 3 \\
University of Queensland & Australia & $9(2.9)$ & 48 & 5.3 & 4 \\
Universität des Saarlandes & Germany & $9(2.9)$ & 274 & 30.4 & 6 \\
Universidade Federal de Sao Paulo & Brazil & $8(2.6)$ & 44 & 5.5 & 3 \\
Liverpool John Moores University & UK & $8(2.6)$ & 238 & 29.8 & 5 \\
\hline
\end{tabular}

$\mathrm{CPP}=$ citations per paper.

\subsection{Prolific Authors and Authorship Pattern}

One-hundred and sixty authors published 313 papers. Eight authors in the list of ten most prolific authors were from Australia, one from Germany and one from Qatar (Table 7). With 25 (8.0\%) published papers and 431 citations (17.2 citations per paper; h-index =9), Shona L. Halson of Australian Catholic University (Australia) was the most productive author. The next three authors from Central Queensland University (Australia) were Charli Sargent with $20(6.4 \%)$ publications and 286 citations (14.3 citations per paper; h-index $=9)$, Michele Lastella with $16(5.11 \%)$ publications and 216 citations (13.5 citations per paper; h-index = 5) and Gregory D. Roach with $16(5.1 \%)$ publications and 221 citations (13.8 citations per paper; h-index =7). However, Tim F. Meyer of Universität des Saarlandes, Saarbrucken (Germany), with $9(2.9 \%)$ publications and 274 citations, had the highest citations per paper (30.4). Michele Lastella had the highest number of papers (9 out of 16) published as the first author, whereas, Charli Sargent has the highest number of papers (11 out of 20 ) published as a senior/last author.

Table 7. Top 10 highly productive authors for sleep research in athletes $(n=313)$.

\begin{tabular}{|c|c|c|c|c|c|c|c|}
\hline Author & Papers (\%) & FAP & SAP & Citations & CPP & h-index * & Affiliation ** \\
\hline Halson, S.L. & $25(8.0)$ & 3 & 4 & 431 & 17.2 & 9 & $\begin{array}{l}\text { Australian Catholic University, } \\
\text { North Sydney, NSW, Australia }\end{array}$ \\
\hline Sargent, C. & $20(6.4)$ & 5 & 11 & 286 & 14.3 & 9 & $\begin{array}{l}\text { Central Queensland University, } \\
\text { Adelaide, Australia }\end{array}$ \\
\hline Lastella, M. & $16(5.1)$ & 9 & 1 & 216 & 13.5 & 5 & $\begin{array}{l}\text { Central Queensland University, } \\
\text { Adelaide, Australia }\end{array}$ \\
\hline Roach, G.D. & $16(5.1)$ & 1 & 4 & 221 & 13.8 & 7 & $\begin{array}{l}\text { Central Queensland University, } \\
\text { Adelaide, Australia }\end{array}$ \\
\hline Duffield, R. & $15(4.8)$ & 1 & 1 & 400 & 26.7 & 9 & $\begin{array}{l}\text { University of Technology Sydney, } \\
\text { Sydney, Australia }\end{array}$ \\
\hline Dawson, B. & $9(2.9)$ & 0 & 0 & 110 & 12.2 & 5 & $\begin{array}{l}\text { West Coast Eagles Football Club, } \\
\text { Perth, Australia }\end{array}$ \\
\hline Meyer, T. & $9(2.9)$ & 0 & 6 & 274 & 30.4 & 6 & $\begin{array}{l}\text { Universität des Saarlandes, } \\
\text { Saarbrucken, Germany }\end{array}$ \\
\hline Eastwood, P.R. & $8(2.6)$ & 0 & 7 & 74 & 9.3 & 4 & $\begin{array}{l}\text { University of Western Australia, } \\
\text { Perth, Australia }\end{array}$ \\
\hline Gore, C.J. & $8(2.6)$ & 0 & 0 & 167 & 20.9 & 7 & $\begin{array}{l}\text { Australian Institute of Sport, } \\
\text { Canberra, Australia }\end{array}$ \\
\hline Chamari, K. & $7(2.2)$ & 0 & 2 & 60 & 8.6 & 5 & $\begin{array}{l}\text { Aspetar Orthopaedic and Sports } \\
\text { Medicine Hospital, Doha, Qatar }\end{array}$ \\
\hline
\end{tabular}




\subsection{Network Visualisation Map (Collaborative Networks and Research Trends)}

The network visualisation map yielded 6 clusters of 38 keywords for author keywords with minimum occurrences of 5. There were a total of 225 links, which indicates links of an item with other items, with a total link strength (total strength of the links of an item with other items) of 443 (minimum link strength $=3$, maximum link strength $=112$ ) and occurrence ranging from 5 to 76 . This suggests that there were 225 pairs of 38 keywords having the co-occurrence links. In simple words, sleep quality and athlete co-occur together making a link of co-occurrence. This link has a link strength, represented by the number of documents in which two keywords occur together. The sum of the link strengths, reflective the pattern in which group of keywords co-occur, was 443 . The top 15 most common author keywords were sleep, athletes, recovery, actigraphy, performance, fatigue, exercise, athlete, sleep deprivation, sleep quality, athletic performance, team sports, sports, concussion, and soccer (Figure 3). There were eight keywords each in cluster 1 and 2, seven keywords in cluster 3 and 4, five keywords in cluster 5, and three keywords in cluster 6. Keywords in the same cluster are represented by the same colour and usually co-occur together. For instance, the yellow-coloured cluster shows that adolescence, fatigue, football, regeneration, soccer, stress, training are commonly listed together.

\& vosviewer

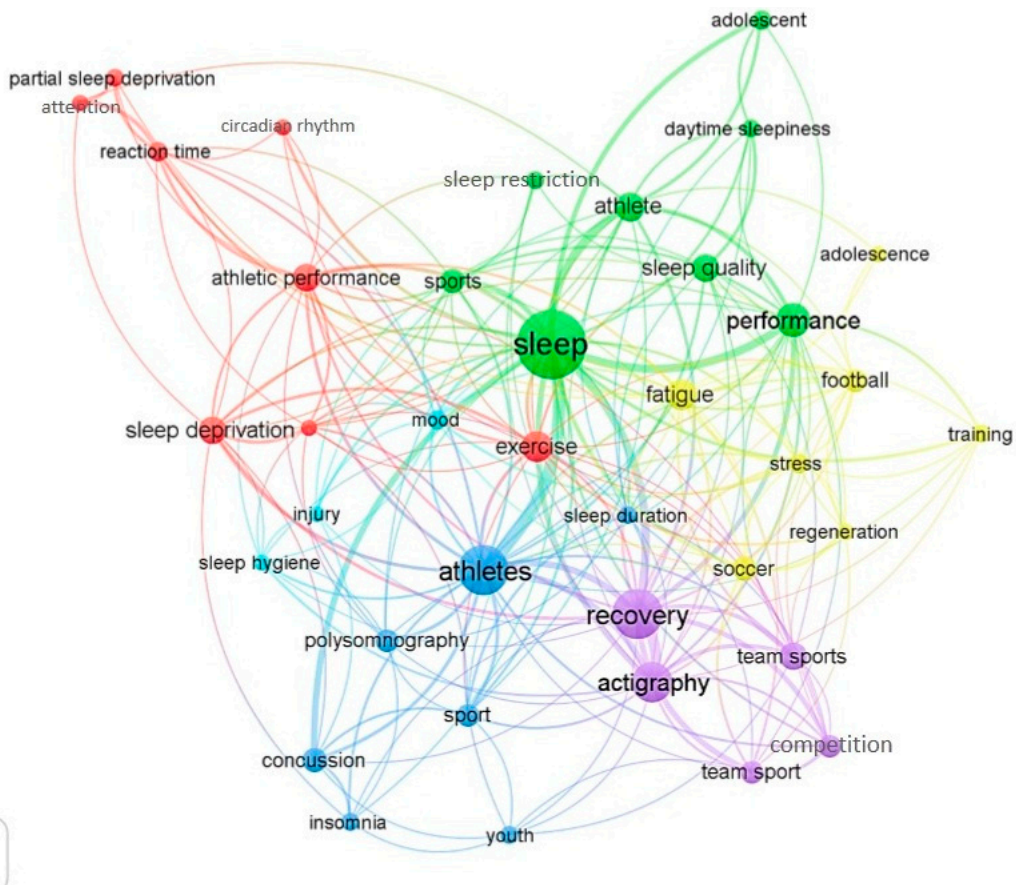

Figure 3. Network visualisation map for author keywords with a minimum occurrence of 5.

\section{Discussion}

This study provides a comprehensive bibliometric analysis of the published scientific literature examining sleep research in athletes. Over the last decade (2010-2019) there has been substantial growth in research pertaining to sleep in athletes, with 257 new research articles published. Similar to sports nutrition research [61], sleep research in athletes has progressed, due to the well-established importance of sleep toward optimising recovery and performance [59,62]. This trend may reflect the growing interests of athletic/sporting organisations and the scientific community in understanding the critical role sleep has on athlete health, recovery and performance. Technological advancements in sleep measurement, such as the implementation of research-grade accelerometers in athlete populations may have also contributed to the rise in research output [63].

The increased production of sleep research in athletes in the past decade (2010-2019) was led by Australia, closely followed by the United States of America, France, the United Kingdom, and 
Germany. This increased production, mostly in developed countries, may reflect the globalisation of sport and the large investments made by governing bodies [64,65]. For example, in the 2016-2017 financial year, the Australian government committed \$101 million (AUD) to high performance sports funding [66]. For many countries, investment into sport is viewed in light of a virtuous cycle such that elite sporting success offers international prestige for the nation, a certain 'feel-good factor among the people' and ultimately can increase sport participation throughout the population [65]. Further, investment into sports specific scientific research and employment of sports scientists and specialist consultants (e.g., dedicated sports scientists) is becoming more prevalent and contributes to improving sporting performance [67].

In this study, literature investigating sleep in athletes was dominated by multi-authored articles, articles written in English and original investigations. Previous bibliometric studies indicate that original articles and papers are written in English typically make up the majority of the assessed literature [27,32-34]. In the current study, $40 \%$ of the publications (average 14 citations per publication) were from the top ten journals, which had an average impact factor of 4.0 . Further, $70 \%$ of the top ten journals were from the list of top $25 \%$ (i.e., Q1) of journals for at least one of their classified sub-disciplines. According to the article type classification in the Scopus database, five reviews were included in the top 25 highly cited papers covering topics, such as sleep, recovery, circadian rhythms, cognitive and athletic performance. From these metrics, it is evident that sleep research in athletes has predominantly focused on a) monitoring athletes sleep during training and competition [15,16,68,69], b) the physiological and psychological demands of different sports on sleep [70-72], c) examining factors, such as travel [73], altitude [74,75], training load [71], and competition anxiety [16,76,77] that either impact athletes' ability to sleep or d) how psychological well-being [18,78], and recovery [71] are influenced by sleep. The keyword visualisation map illustrates the bi-directional relationships between sleep, recovery and performance (Figure 3). Data derived from the highest cited papers and visualisation map indicate that most research is based on travel, the timing of training/competition, the influence of training load on sleep and injury [15-17,71,73]. Further, the importance of sleep before and after sport-related concussions has also become a topic of growing interest $[79,80]$.

This bibliometric analysis has highlighted areas within the field of sleep and athletes that require further research. Of note, the highest cited paper by Mah et al. showed that extending sleep duration by $1.8 \mathrm{~h}$ per night improved college athletes' overall athletic performance [19]. However, since this publication, there have only been two studies that have found improvements in sport-specific performance following sleep extension [81,82]. In contrast, Famodu et al. observed no differences in performance following sleep extension [83]. Given the significant impact of Mah et al. in terms of citation count [19], it is evident that future investigations need to implement sleep extension protocols to ensure the recommendations of extending sleep duration are based on sound empirical evidence.

Another strategy to improve sleep duration in athletes that have been largely understudied with the sleep research in athletes is napping. For an athlete, a daytime nap is often employed to counteract sleep debt, increase sleep duration over a $24 \mathrm{~h}$ period and reduce daytime sleepiness [84]. Given the growth sleep research in athletes has received over the past decade, it seems negligent that few studies have included nap duration as part of an athletes' sleep over a $24 \mathrm{~h}$ period [14,19]. Moving forward, it is imperative that studies collect data on the timing and duration of naps taken by athletes at a range of different times (e.g., pre- and post-competition, during an intensive training period). In doing so, total sleep duration over a $24 \mathrm{~h}$ period can be obtained, rather than just the main night time sleep periods. Therefore, future studies should consider examining the benefits and risks of napping in relation to athlete recovery and performance. Other areas of future research include the bi-directional relationships between sleep and injury, as well as the impact of sports related concussion on subsequent sleep.

The main strengths of the current study comprising of robust procedures were: Rigorous selection criteria and assessment of titles-abstracts and full-text (in some cases) for the suitability, the inclusion of journal publications without restricting the language of publication, and presentation of citation 
impact through h-index after limiting author' self-citations and citation density for top-cited papers. However, the current study has some limitations, which should be acknowledged. Although we aimed to include all the relevant journal publications on sleep research in athletes available in the Scopus database, non-indexed journals and publications might not have been recognised. In addition, most of the journals indexed in the scholarly databases like Scopus are published in English, which suggests that the papers published in non-English journals and in journals not indexed in the Scopus database were, therefore, not included in the study $[27,85]$. Secondly, the bibliometric indicators presented in the current study were based on the data directly imported from the Scopus database and in some cases, there might be inaccuracies in the names of authors, institutions, and in the categorisation of papers by document type-an inherent limitation of bibliographic databases $[27,85]$. Finally, the title search is commonly used in bibliometric studies and is expected to yield accurate data, thereby reducing the potential for false-positive and false-negative results. However, this strategy might miss the publications where keywords are mentioned in the title of the paper. We tried to limit the inclusion of false-positive by manually reviewing the title and abstract of each paper, but we could not limit the likelihood of false-negatives. It should be noted that these limitations are common to bibliometric studies $[27,32-34,41]$.

\section{Conclusions}

This is the first study to examine the bibliometric parameters of sleep research in athletes since the first published study in 1966. The present study showed the sleep research in athletes has grown considerably over the last decade (2010-2019). The increasing number of citations over and a relatively high h-index of the retrieved papers indicates the importance of sleep for athletes, sports practitioners, researchers, clinicians and policy makers. Future research in this field should go beyond sleep monitoring, and focus on interventions (e.g., sleep extension, napping) to improve the sleep of athletes.

Supplementary Materials: The following are available online at http://www.mdpi.com/2624-5175/2/2/10/s1.

Author Contributions: For research articles with several authors, a short paragraph specifying their individual contributions must be provided. The following is each author's contribution: Conceptualisation, methodology, validation, investigation, writing — original draft preparation, writing—review and editing, M.L.; conceptualisation, methodology, software, formal analysis, visualisation, writing-original draft preparation, A.R.M.; conceptualisation, methodology, validation, writing-review and editing, supervision, G.E.V. All authors have read and agreed to the published version of the manuscript.

Funding: This research received no external funding.

Conflicts of Interest: One of the authors of the current paper (ML) was among the top ten authors on sleep research in athletes. He did not participate in data analyses and therefore, did not have any influence on the results. The authors declare no conflict of interest.

\section{Appendix A}

Search strategy used for the literature search:

TITLE ("sleep*" OR "sleep quantity" OR "sleep quality" OR "sleep-hygiene" OR "sleep disturbance" OR "nap*" OR "wak" OR “wake") AND TITLE ("athlet" OR "player*" OR "sport*"

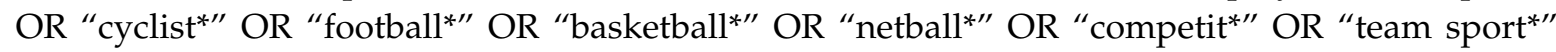
OR “individual sport*" OR "cricket*” OR "game ${ }^{* \prime}$ OR "handball*” OR “baseball*” OR "softball*” OR "rugby" OR "cycling" OR "soccer" OR "*hockey" OR "futsal" OR "volleyball" OR "korfball" OR "lacrosse" OR "curling" OR "polo" OR "*swimming" OR "rowing" OR "mountain biking" OR "triathlon" OR "race walking" OR "canoeing" OR "diving" OR "running" OR "judo" OR "*skating" OR "ballet" OR "skiing" OR "snowboarding" OR "taekwondo" OR "archery" OR "badminton" OR "bmx" OR "bocce" OR "bowling" OR "boxing" OR "cheerleading" OR "croquet" OR "dance" OR "fencing" OR "golf" OR "gymnastics" OR "martial arts" OR "squash" OR "throw" OR "*tennis" OR "karate" OR "touch football* OR "ice-hockey" OR "synchronised swimming" OR "swimming" OR "speed skating" OR "figure skating" OR "table tennis" OR "weight lift" OR "roller skating" OR "motor sport" 
"orienteering" OR "equestrian" OR "wheelchair prop" OR "water polo" OR "abseiling" OR "surfing") AND PUBYEAR > 1965 AND (LIMIT-TO (SRCTYPE, “j”)) AND (EXCLUDE (DOCTYPE, “er"))

\section{Appendix B}

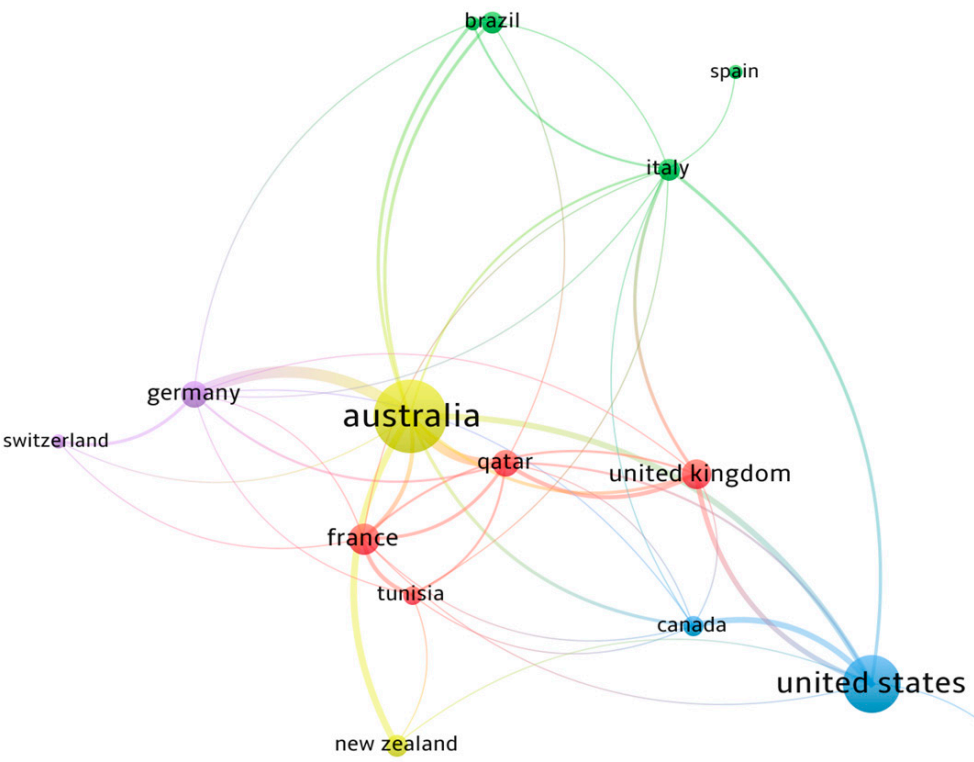

VOSviewer

Figure A1. Network visualisation map for countries with minimum five papers.

Co-authorship analysis for countries with minimum five papers produced the network visualisation map of 15 countries in five clusters, each represented by a distinct colour. The strongest collaboration was present among Australia-Germany (link strength =13), Australia-Qatar (link strength $=10$ ), and Australia-New Zealand (link strength = 7).

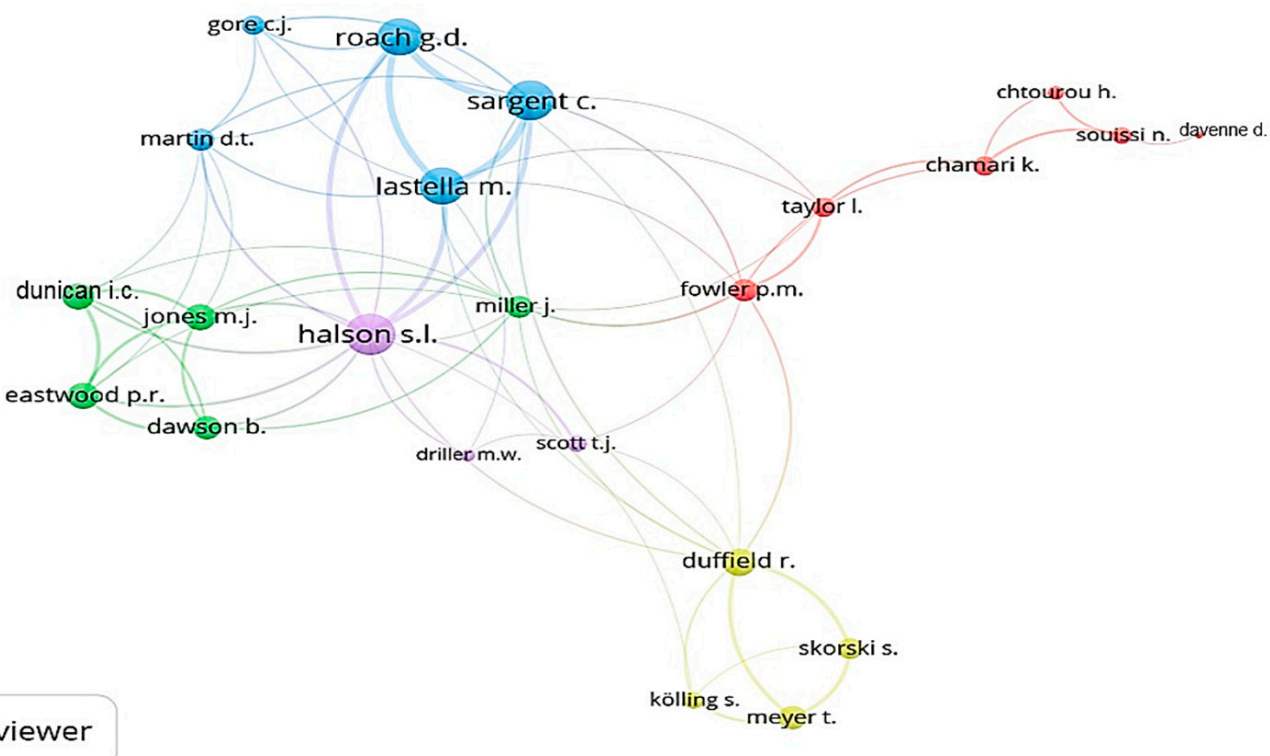

Figure A2. Network visualisation map for authors with minimum five papers. 


\section{References}

1. Dattilo, M.; Antunes, H.; Medeiros, A.; Neto, M.M.; Souza, H.S.; Tufik, S.; de Mello, M.T. Sleep and muscle recovery: Endocrinological and molecular basis for a new and promising hypothesis. Med. Hypotheses. 2011, 77, 220-222. [CrossRef] [PubMed]

2. Adam, K.; Oswald, I. Protein synthesis, bodily renewal and the sleep-wake cycle. Clin. Sci. (Lond.) 1983, 65, 561-567. [CrossRef] [PubMed]

3. Silber, M.H.; Ancoli-Israel, S.; Bonnet, M.H.; Chokroverty, S.; Grigg-Damberger, M.M.; Hirshkowitz, M.; Kapen, S.; Keenan, S.A.; Kryger, M.H.; Penzel, T. The visual scoring of sleep in adults. J. Clin. Sleep Med. 2007, 3, 121-131. [CrossRef]

4. Dinges, D.F.; Pack, F.; Williams, K.; Gillen, K.A.; Powell, J.W.; Ott, G.E.; Aptowicz, C.; Pack, A.I. Cumulative sleepiness, mood disturbance and psychomotor vigilance performance decrements during aweek of sleep restricted to 4-5 hours per night. Sleep 1997, 20, 267-277.

5. Van Dongen, H.P.A.; Maislin, G.; Mullington, J.M.; Dinges, D.F. The cumulative cost of additional wakefulness: Dose-response effects on neurobehavioral functions and sleep physiology from chronic sleep restriction and total sleep deprivation. Sleep 2003, 26, 117-126. [CrossRef]

6. Scott, J.P.R.; McNaughton, L.R.; Polman, R.C.J. Effects of sleep deprivation and exercise on cognitive, motor performance and mood. Physiol. Behav. 2006, 87, 396-408. [CrossRef]

7. Knutson, K.L. Impact of sleep and sleep loss on glucose homeostasis and appetite regulation. Sleep Med. Clin. 2007, 2, 187-197. [CrossRef]

8. Spiegel, K.; Tasali, E.; Penev, P.; Van Cauter, E. Brief communication: Sleep curtailment in healthy young men is associated with decreased leptin levels, elevated ghrelin levels, and increased hunger and appetite. Ann. Intern. Med. 2004, 141, 846-850. [CrossRef]

9. Vgontzas, A.N.; Zoumakis, E.; Bixler, E.O.; Lin, H.M.; Follett, H.; Kales, A.; Chrousos, G.P. Adverse effects of modest sleep restriction on sleepiness, performance, and inflammatory cytokines. J. Clin. Endocrinol. Metab. 2004, 89, 2119-2126. [CrossRef]

10. Roberts, S.S.H.; Teo, W.-P.; Warmington, S.A. Effects of training and competition on the sleep of elite athletes: A systematic review and meta-analysis. Br. J. Sports Med. 2019, 53, 513-522. [CrossRef]

11. Bird, S.P. Sleep, recovery, and athletic performance: A brief review and recommendations. Strength Cond. J. 2013, 35, 43-47. [CrossRef]

12. Baekeland, F.; Lasky, R. Exercise and sleep patterns in college athletes. Percept. Mot. Ski. 1966, 23, $1203-1207$. [CrossRef]

13. Taylor, S.R.; Rogers, G.G.; Driver, H.S. Effects of training volume on sleep, psychological, and selected physiological profiles of elite female swimmers. Med. Sci. Sports Exerc. 1997, 29, 688-693. [CrossRef]

14. Sargent, C.; Lastella, M.; Halson, S.L.; Roach, G.D. The impact of training schedules on the sleep and fatigue of elite athletes. Chronobiol. Int. 2014, 31, 1160-1168. [CrossRef]

15. Lastella, M.; Roach, G.D.; Halson, S.L.; Martin, D.T.; West, N.P.; Sargent, C. Sleep/wake behaviour of endurance cyclists before and during competition. J. Sports Sci. 2015, 33, 293-299. [CrossRef]

16. Juliff, L.E.; Halson, S.L.; Peiffer, J.J. Understanding sleep disturbance in athletes prior to important competitions. Sci. Med. Sport 2015, 18, 13-18. [CrossRef]

17. Milewski, M.D.; Skaggs, D.L.; Bishop, G.A.; Pace, J.L.; Ibrahim, D.A.; Wren, T.A.; Barzdukas, A. Chronic lack of sleep is associated with increased sports injuries in adolescent athletes. J. Pediatr. Orthop. 2014, 34, 129-133. [CrossRef]

18. Brand, S.; Gerber, M.; Beck, J.; Hatzinger, M.; Pühse, U.; Holsboer-Trachsler, E. High exercise levels are related to favorable sleep patterns and psychological functioning in adolescents: A comparison of athletes and controls. J. Adolesc. Health 2010, 46, 133-141. [CrossRef]

19. Mah, C.D.; Mah, K.E.; Kezirian, E.J.; Dement, W.C. The effects of sleep extension on the athletic performance of collegiate basketball players. Sleep 2011, 34, 943-950. [CrossRef]

20. Wallin, J.A. Bibliometric methods: Pitfalls and possibilities. Basic Clin. Pharmacol. Toxicol. 2005, 97, $261-275$. [CrossRef]

21. Van Raan, A.F. Advances in bibliometric analysis: Research performance assessment and science mapping. In Bibliometrics: Use and Abuse in the Review of Research Performance; Blockmans, W., Engwall, L., Weaire, D., Eds.; Portland Press Ltd.: London, UK, 2014; pp. 17-28. 
22. Ellegaard, O.; Wallin, J.A. The bibliometric analysis of scholarly production: How great is the impact? Scientometrics 2015, 105, 1809-1831. [CrossRef]

23. Ellegaard, O. The application of bibliometric analysis: Disciplinary and user aspects. Scientometrics 2018, 116, 181-202. [CrossRef]

24. Narin, F.; Olivastro, D.; Stevens, K. Bibliometrics theory, practice and problems. Eval. Rev. 1994, 18, 65-76. [CrossRef]

25. Rosas, S.R.; Kagan, J.M.; Schouten, J.T.; Slack, P.A.; Trochim, W.M. Evaluating research and impact: A bibliometric analysis of research by the NIH/NIAID HIV/AIDS clinical trials networks. PLoS ONE 2011, 6, e17428. [CrossRef]

26. Gonzalez, L.-M.; García-Massó, X.; Pardo-Ibañez, A.; Peset, F.; Devis-Devis, J. An author keyword analysis for mapping Sport Sciences. PLoS ONE 2018, 13, e0201435. [CrossRef]

27. Memon, A.R.; Vandelanotte, C.; Olds, T.; Duncan, M.J.; Vincent, G.E. Research Combining Physical Activity and Sleep: A Bibliometric Analysis. Percept. Mot. Skills. 2019. [CrossRef]

28. Benton, A.D.; Benton, D.C. Evolution of physiotherapy scholarship: A comparative bibliometric analysis of two decades of English published work. Physiother. Res. Int. 2019, 24, e1760. [CrossRef]

29. Benton, D.C.; Cusack, L.; Jabbour, R.; Penney, C. A bibliographic exploration of nursing's scope of practice. Int. Nurs. Rev. 2017, 64, 224-232. [CrossRef]

30. Brown, T.; Gutman, S.A.; Ho, Y.-S.; Fonk, K.N.K. A bibliometric analysis of occupational therapy publications. Scand. J. Occup. Ther. 2018, 25, 1-14. [CrossRef]

31. Sharma, N.; Bairwa, M.; Gowthamghosh, B.; Gupta, S.D.; Mangal, D.K. A bibliometric analysis of the published road traffic injuries research in India, post-1990. Health Res. Policy Syst. 2018, 16, 18. [CrossRef]

32. Sweileh, W.M. Global research output on HIV/AIDS-related medication adherence from 1980 to 2017. BMC Health Serv. Res. 2018, 18, 765. [CrossRef] [PubMed]

33. Sweileh, W.M. Research trends on human trafficking: A bibliometric analysis using Scopus database. Glob. Health 2018, 14, 106. [CrossRef] [PubMed]

34. Sweileh, W.M.; Al-Jabi, S.W.; AbuTaha, A.S.; Zyoud, S.H.; Anayah, F.M.A.; Sawalha, A.F. Bibliometric analysis of worldwide scientific literature in mobile-health: 2006-2016. BMC Med. Inform. Decis. Mak. 2017, 17, 72. [CrossRef]

35. Robert, C.; Wilson, C.S.; Gaudy, J.-F.; Arreto, C.-D. A year in review: Bibliometric glance at sleep research literature in medicine and biology. Sleep Biol. Rhythm. 2006, 4, 160-170. [CrossRef]

36. Robert, C.; Wilson, C.S.; Gaudy, J.-F.; Arreto, C.-D. The evolution of the sleep science literature over 30 years: A bibliometric analysis. Scientometrics 2007, 73, 231-256. [CrossRef]

37. Webb, W.B. Trends in the sleep literature: 1968-1988. Sleep 1991, 14, 178-179. [CrossRef]

38. Falagas, M.E.; Pitsouni, E.I.; Malietzis, G.A.; Pappas, G. Comparison of PubMed, Scopus, web of science, and Google scholar: Strengths and weaknesses. FASEB J. 2008, 22, 338-342. [CrossRef]

39. Kulkarni, A.V.; Aziz, B.; Shams, I.; Busse, J.W. Comparisons of citations in Web of Science, Scopus, and Google Scholar for articles published in general medical journals. JAMA 2009, 302, 1092-1096. [CrossRef]

40. Baas, J.; Schotten, M.; Plume, A.; Cote, G.; Karimi, R. Scopus as a curated, high-quality bibliometric data source for academic research in quantitative science studies. Quant. Sci. Stud. 2020, 1, 377-386. [CrossRef]

41. Sweileh, W.M.; Huijer, H.A.-S.; Al-Jabi, S.W.; Zyoud, S.H.; Sawalha, A.F. Nursing and midwifery research activity in Arab countries from 1950 to 2017. BMC Health Serv. Res. 2019, 19, 340. [CrossRef]

42. Grant, M.J.; Booth, A. A typology of reviews: An analysis of 14 review types and associated methodologies. Health Inf. Libr. J. 2009, 26, 91-108. [CrossRef]

43. Møller, A.M.; Myles, P.S. What makes a good systematic review and meta-analysis? Br. J. Anaesth. 2016, 117, 428-430. [CrossRef] [PubMed]

44. Bonnar, D.; Bartel, K.; Kakoschke, N.; Lang, C. Sleep Interventions Designed to Improve Athletic Performance and Recovery: A Systematic Review of Current Approaches. Sports Med. 2018, 48, 683-703. [CrossRef] [PubMed]

45. Claudino, J.G.; Gabbett, T.; de Sá Souza, H.; Simim, M.; Fowler, P.; de Alcantara Borba, D.; Melo, M.; Bottino, A.; Loturco, I.; D'Almeida, V.; et al. Which parameters to use for sleep quality monitoring in team sport athletes? A systematic review and meta-analysis. BMJ Open Sport Exerc. Med. 2019, 5, e000475. [CrossRef] [PubMed] 
46. Williams, S.J.; Kendall, L.R. A profile of sports science research (1983-2003). J. Sci. Med. Sport 2007, 10, $193-200$. [CrossRef] [PubMed]

47. MacMahon, C.; Parrington, L. Not All Athletes Are Equal, But Don't Call Me an Exerciser: Response to Araujo and Scharhag1. Scand. J. Med. Sci. Sports 2017, 27, 904-906. [CrossRef]

48. McKinney, J.; Velghe, J.; Fee, J.; Isserow, S.; Drezner, J.A. Defining Athletes and Exercisers. Am. J. Cardiol. 2019, 123, 532-535. [CrossRef]

49. Swann, C.; Moran, A.; Piggott, D. Defining elite athletes: Issues in the study of expert performance in sport psychology. Psychol. Sport Exerc. 2015, 16, 3-14. [CrossRef]

50. Bradshaw, C.J.; Brook, B.W. How to rank journals. PLoS ONE 2016, 11, e0149852. [CrossRef]

51. Brown, T.; Gutman, S.A. Impact factor, eigenfactor, article influence, scopus SNIP, and SCImage journal rank of occupational therapy journals. Scand. J. Occup. Ther. 2019, 26, 475-483. [CrossRef]

52. Agarwal, A.; Durairajanayagam, D.; Tatagari, S.; Esteves, S.C.; Harlev, A.; Henkel, R.; Roychoudhury, S.; Homa, S.; Puchalt, N.G.; Ramasamy, R.; et al. Bibliometrics: Tracking research impact by selecting the appropriate metrics. Asian J. Androl. 2016, 18, 296-309. [CrossRef] [PubMed]

53. Hirsch, J.E. An index to quantify an individual's scientific research output. Proc. Natl. Acad. Sci. USA 2005, 102, 16569-16572. [CrossRef] [PubMed]

54. Müller, A.M.; Ansari, P.; Ebrahim, N.A.; Khoo, S. Physical Activity and Aging Research: A Bibliometric Analysis. J. Aging Phys. Act. 2016, 24, 476-483. [CrossRef] [PubMed]

55. Ho, Y.-S. Classic articles on social work field in Social Science Citation Index: A bibliometric analysis. Scientometrics 2013, 98, 137-155. [CrossRef]

56. Chuang, K.-Y.; Wang, M.-H.; Ho, Y.-S. High-impact papers presented in the subject category of water resources in the essential science indicators database of the institute for scientific information. Scientometrics 2011, 87, 551-562. [CrossRef]

57. van Eck, N.J.; Waltman, L. Software survey: VOSviewer, a computer program for bibliometric mapping. Scientometrics 2009, 84, 523-538. [CrossRef]

58. van Eck, N.J.; Waltman, L. Citation-based clustering of publications using CitNetExplorer and VOSviewer. Scientometrics 2017, 111, 1053-1070. [CrossRef]

59. Fullagar, H.H.; Skorski, S.; Duffield, R.; Hammes, D.; Coutts, A.J.; Meyer, T. Sleep and athletic performance: The effects of sleep loss on exercise performance, and physiological and cognitive responses to exercise. Sports Med. 2015, 45, 161-186. [CrossRef]

60. Halson, S.L. Sleep in elite athletes and nutritional interventions to enhance sleep. Sports Med. 2014, 44, 13-23. [CrossRef]

61. Burke, L.M.; Castell, L.M.; Casa, D.J.; Close, G.L.; Costa, R.J.S.; Desbrow, B.; Halson, S.L.; Lis, D.M.; Melin, A.K.; Peeling, P.; et al. International Association of Athletics Federations Consensus Statement 2019: Nutrition for Athletics. Int. J. Sport Nutr. Exerc. Metab. 2019, 29, 73-84. [CrossRef]

62. Samuels, C. Sleep, recovery, and performance: The new frontier in high-performance athletics. Neurol. Clin. 2008, 26, 169-180. [CrossRef] [PubMed]

63. de Zambotti, M.; Cellini, N.; Goldstone, A.; Colrain, I.M.; Baker, F.C. Wearable Sleep Technology in Clinical and Research Settings. Med. Sci. Sports Exerc. 2019, 51, 1538-1557. [CrossRef] [PubMed]

64. Sotiriadou, K.P.; Shilbury, D. Australian elite athlete development: An organisational perspective. Sport Manag. Rev. 2009, 12, 137-148. [CrossRef]

65. Grix, J.; Carmichael, F. Why do governments invest in elite sport? A polemic. Int. J. Sport Policy Polit. 2012, 4, 73-90. [CrossRef]

66. \$10 Million Funding Boost for Tokyo 2020 Athletes. Available online: https://www.health.gov.au/ministers/ the-hon-greg-hunt-mp/media/10-million-funding-boost-for-tokyo-2020-athletes (accessed on 14 July 2019).

67. De Bosscher, V.; De Knop, P.; Van Bottenburg, M.; Shibli, S. A conceptual framework for analysing sports policy factors leading to international sporting success. Eur. Sport Manag. Q. 2006, 6, 185-215. [CrossRef]

68. Sargent, C.; Roach, G.D. Sleep duration is reduced in elite athletes following night-time competition. Chronobiol. Int. 2016, 33, 667-670. [CrossRef] [PubMed]

69. Sargent, C.; Halson, S.; Roach, G.D. Sleep or swim? Early-morning training severely restricts the amount of sleep obtained by elite swimmers. Eur. J. Sport Sci. 2014, 14, S310-S315. [CrossRef]

70. Juliff, L.E.; Peiffer, J.J.; Halson, S.L. Night Games: Physiological, Neuroendocrine and Psychometric Mechanisms to Explain Poor Sleep. Int. J. Sports Physiol. Perform. 2018, 13, 867-873. [CrossRef] 
71. Knufinke, M.; Nieuwenhuys, A.; Geurts, S.A.E.; Møst, E.I.S.; Maase, K.; Moen, M.H.; Coenen, A.M.L.; Kompier, M.A.J. Train hard, sleep well? Perceived training load, sleep quantity and sleep stage distribution in elite level athletes. J. Sci. Med. Sport 2018, 21, 427-432. [CrossRef]

72. Miller, D.J.; Sargent, C.; Vincent, G.E.; Raoch, G.D.; Halson, S.L.; Lastella, M. Sleep/Wake Behaviours in Elite Athletes from Three Different Football Codes. J. Sports Sci. Med. 2017, 16, 604-605.

73. Fowler, P.; Duffield, R.; Vaile, J. Effects of simulated domestic and international air travel on sleep, performance, and recovery for team sports. Scand. J. Med. Sci. Sports 2015, 25, 441-451. [CrossRef] [PubMed]

74. Lastella, M.; Roach, G.D.; Halson, S.L.; Gore, C.J.; Garvican-Lewis, L.A.; Sargent, C. The effects of transmeridian travel and altitude on sleep: Preparation for football competition. J. Sports Sci. Med. 2014, 13, 718-720. [PubMed]

75. Roach, G.D.; Schmidt, W.F.; Aughey, R.J.; Bourdon, P.C.; Soria, R.; Claros, J.C.; Garvican-Lewis, L.A.; Buchheit, M.; Simpson, B.M.; Hammond, K.; et al. The sleep of elite athletes at sea level and high altitude: A comparison of sea-level natives and high-altitude natives (ISA3600). Br. J. Sports Med. 2013, 47, i114-i120. [CrossRef] [PubMed]

76. Erlacher, D.; Ehrlenspiel, F.; Adegbesan, O.A.; El-Din, H.G. Sleep habits in German athletes before important competitions or games. J. Sports Sci. 2011, 29, 859-866. [CrossRef] [PubMed]

77. Lastella, M.; Lovell, G.P.; Sargent, C. Athletes' precompetitive sleep behaviour and its relationship with subsequent precompetitive mood and performance. Eur. J. Sport Sci. 2014, 14, S123-S130. [CrossRef]

78. Van Ryswyk, E.; Weeks, R.; Bandick, L.; O’Keefe, M.; Vakulin, A.; Catcheside, P.; Barger, L.; Potter, A.; Poulos, N.; Wallace, J.; et al. A novel sleep optimisation programme to improve athletes' well-being and performance. Eur. J. Sport Sci. 2017, 17, 144-151. [CrossRef]

79. McClure, D.J.; Zuckerman, S.L.; Kutscher, S.J.; Gregory, A.J.; Solomon, G.S. Baseline neurocognitive testing in sports-related concussions: The importance of a prior night's sleep. Am. J. Sports Med. 2014, 42, 472-478. [CrossRef]

80. Gosselin, N.; Lassonde, M.; Petit, D.; Leclerc, S.; Mongrain, V.; Collie, A.; Montplaisir, J. Sleep following sport-related concussions. Sleep Med. 2009, 10, 35-46. [CrossRef]

81. Swinbourne, R.; Miller, J.; Smart, D.; Dulson, D.K.; Gill, N. The effects of sleep extension on sleep, performance, immunity and physical stress in rugby players. Sports (Basel) 2018, 6, e42. [CrossRef]

82. Schwartz, J.; Simon, R.D. Sleep extension improves serving accuracy: A study with college varsity tennis players. Physiol. Behav. 2015, 151, 541-544. [CrossRef]

83. Famodu, O.; Montgomery-Downs, H.; Thomas, J.; Gilleland, D.L.; Bryner, R.W.; Olfert, M.D. Impact of a single week of sleep extension on performance, mood, and nutrition among female college track athletes. Sleep 2017, 40, A32. [CrossRef]

84. Davies, D.J.; Graham, K.S.; Chow, C.M. The effect of prior endurance training on nap sleep patterns. Int. J. Sports Physiol. Perform. 2010, 5, 87-97. [CrossRef] [PubMed]

85. Memon, A.R. Bibliometric analysis of the Journal of Pakistan Medical Association during the period from 1965 to 2018. J. Pak. Med. Assoc. 2019, 69, 1150-1158. [PubMed]

(C) 2020 by the authors. Licensee MDPI, Basel, Switzerland. This article is an open access article distributed under the terms and conditions of the Creative Commons Attribution (CC BY) license (http://creativecommons.org/licenses/by/4.0/). 